\author{
N.V. Bakovets ${ }^{1}$, D.V. Scums ${ }^{1}$, O.B. Tarasova ${ }^{1}$, V.A. Dlugunovich ${ }^{2}$, S.V. Nikanenka ${ }^{2}$ \\ ${ }^{1}$ Belarusian State Institute of Metrology - BelGIM, Minsk, Belarus \\ ${ }^{2}$ B. I. Stepanov Institute of Physics National Academy of Sciences of Belarus, Minsk, Belarus,
}

\title{
NATIONAL STANDARD OF LUMINOUS FLUX OF THE REPUBLIC OF BELARUS
}

This report describes the details of a National standard of luminous flux of the Republic of Belarus. This standard provides calibration of luminous flux and radiant flux in the wavelength range $200 \mathrm{~nm}-1100 \mathrm{~nm}$. The reproduction range of the luminous flux of continuous radiation sources from 10 to $1500 \mathrm{~lm}$. Checking the fidelity, repeatability and reproducibility of the standard, calibration, was done against the four standard lamps calibrated by KRISS (Korea).

Key words: luminous flux, absolute integration sphere, goniospectroradiometer, standard.

\section{Introduction}

In recent years, intensive development of lighting has taken place. It is happened due to the replacement of traditional light sources by new types of radiators such as compact luminescent lamps and LEDs based light sources. Complexity and improving of the ergonomic requirements for general lightning of industrial and residential places, expansion of the use of optical radiation in medicine, industry and agriculture, makes it necessary to solve more complex metrological tasks and accordingly improve the standards in the field of photometry. Development and improvement of the national standards in Belarus is implemented within the framework of the subprogram "Standards of Belarus" of the State scientific and technical program "Development and manufacturing standards of Belarus, unique devices and scientific research facilities." Since 2000 to 2014 in Belarus in the field of photonics and optical radiometry created 5 national and 2working standards [1-2]. During this program was upgraded the standard of the unit of luminous intensity and illuminance. In 2015 BelGIM were completed to create a standard of the unit of luminous flux of light sources, which was approved by the State Committee of Standardization of the Republic of Belarus as national standard. This work is devoted to the the creation of luminous flux standard/.

\section{Methods of the reproduction of the lumi- nous flux}

The radiation flux $\Phi_{e}$, which is emitted by the radiation source, is passed in the environment or percepted by a surface and is measured in watts. In the system of physical photometry it is the primary physical quantity [3]. Corresponding photometric quantity is the luminous flux $\Phi_{\mathrm{v}}$, which is measured in lumens.

Currently, the definition of luminous flux reads as follows [3]: quantity derived from the radiant flux, $\Phi_{\mathrm{e}}$, by evaluating the radiation according to its action upon the CIE standard photometric observer.
Conventional (classical) reproduction of the lumen due, primarily, with the unit of luminous intensity $I_{v}$ reproduction and the use of special instruments such as: integrating sphere or goniometer. Methods of the reproduction of the lumen associated with a unit of illumination $\mathrm{E}_{\mathrm{v}}$, or a unit of the brightness $\mathrm{L}_{\mathrm{v}}$ are less common.

There are two methods of reproduction unit of luminous flux - photometric and goniophotometric [4-5].

Photometric method is based on measurements of the total luminous flux emitted by the light source placed inside the integrating sphere. Integrating sphere is a hollow sphere with an inner surface, painted by matte white non-selective paint. The need to measure the luminous fluxes generated by not only a single light source, but also lamps consisting of light sources and fixtures, entails the use of large integrating sphere with diameters reaching up to 3.5 meters. In those cases when it is necessary to measure the light fluxes created by small-sized light sources (typically less than $20 \mathrm{~mm}$ ) diameter integrating sphere can be reduced to $1 \mathrm{~m}$ or less.

Choosing the diameter of the integrating sphere is a compromise between the desire to maximize the size of it to achieve greater uniformity of light distribution and the desire to provide greater signal from the radiation detector placed inside the sphere by minimize its size.

Goniometric method is based on the measurement of the angular distribution of light characteristics of light sources. Full luminous flux emitted by the light source is calculated by adding the partial light fluxes, provided that the sum of the solid angles fills the space without gaps. The main measuring device is a goniophotometer, which consists of a goniometer and a photometer.

In the created standard reproduction, storage and transmission of luminous flux unit is carried out with use of the photometric and goniophotometric methods. 


\section{The structure of the national stand- ard unit of luminous flux}

Structurally, the standard is designed as separate units interconnected with each other and with other standards in the field of photometry stored in BelGIM. The structure includes a reference photometric, LEDs, goniophotometric and calibration blocks.

The main elements of photometric and the LEDs units are two integrating spheres: ISP 2000 with an inner diameter of $1900 \mathrm{~mm}$ (photometric unit), ISP 1000 with inner diameter of $1000 \mathrm{~mm}$ (LEDs unit) and a spectroradiometer CAS140CT - 156 operating in the wavelength range from 300 to $1100 \mathrm{~nm}$, manufactured by Instrument Systems (Germany). The photometric unit is equipped with working and primary standards on the base of luminous flux Tungsten Halogen lamps W 150, manufactured by Pimacs and KRISS (Korea), and the LED unit - the reference LED sources ACS 540 (manufactured by Instrument Systems) having a light color white, red, blue and green.

The main functions of the photometric unit - reproduction, storage and transmission of luminous flux unit to the subordinate standards and working measuring instruments for measuring of large radiation sources and products based on them. The main functions of the LEDs unit - storage and transmission of luminous flux unit to the subordinate standards and working instruments measuring small-sized light sources and products based on them. Block diagram of the photometric and LED blocks is shown in Figure 1, and the appearance of the photometric and LEDs units - in Figure 2.

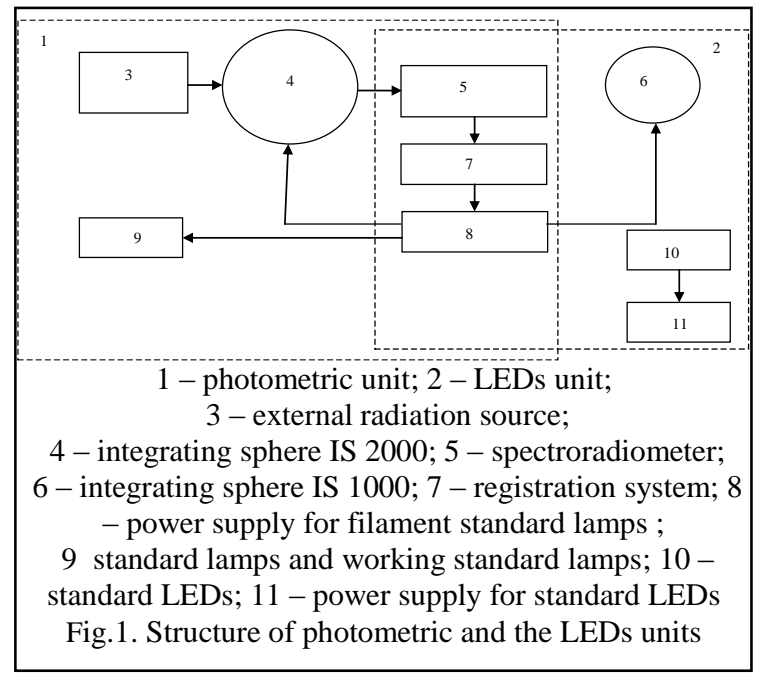

The structure of photometric unit includes an external radiation source, which is the result of joint work of BelGIM, Institute of Physics, National Academy of Sciences of Belarus and Belarusian company "Tsersis Analytic".

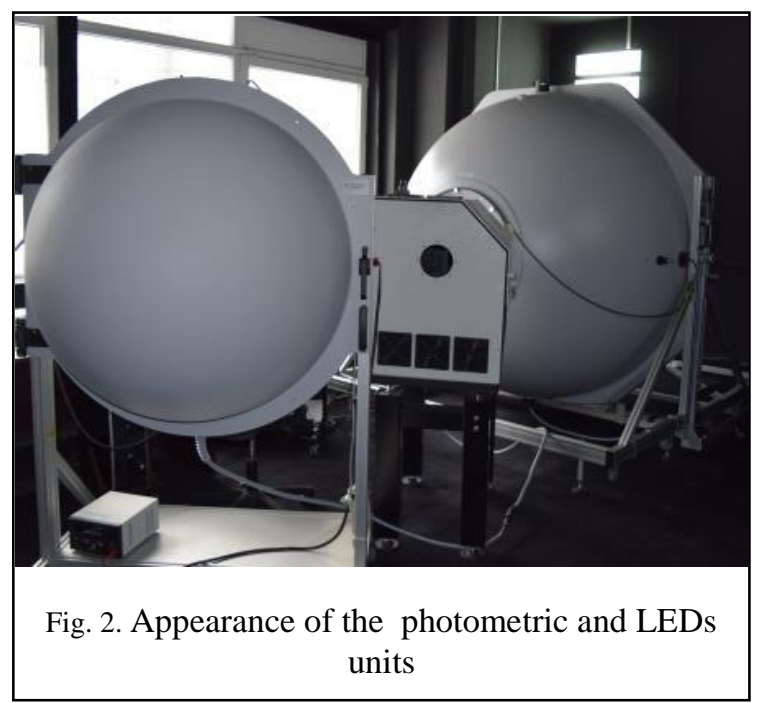

The appearance of the external radiation source is shown in Figure 3.

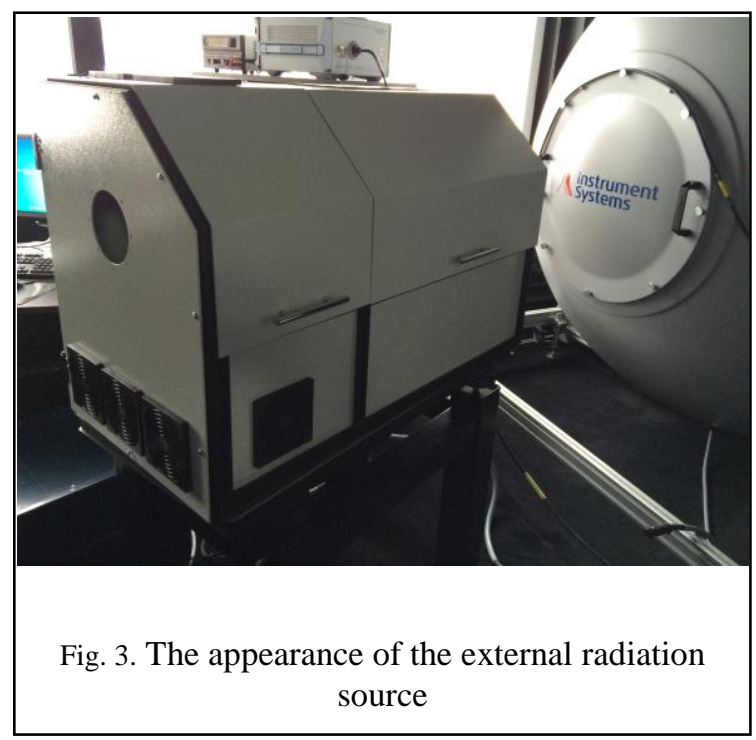

The need to create an external radiation source is that it allows to reproduce unit of the luminous flux by so-called "absolute integrating sphere method"[6]. This method is correlated with the method of the reproduction of the unit of luminous intensity, which is implemented on the National standard NS RB 8-02, located in BelGIM.

Goniophotometric unit is designed to measure the characteristics of the spatial distribution of radiation of different continuous radiation sources, as well as storage and transmission unit of luminous flux of the light source with an arbitrary spatial distribution and largesized lighting products. The basis of goniometric unit is goniometer LGS-350 and spectroradiometer CAS140CT-152 (spectral range from $200 \mathrm{~nm}$ to 800 $\mathrm{nm}$ ) manufactured by Instrument Systems (Germany).

Calibration system of the integrating sphere, provided traceability to national standards of units of luminous intensity and illuminance NS RB 8-02, the unit of spectral responsivity of the optical detectors 
NS RB 17-10, working standard of the unit of length IS RB 1-96. All of them a National standards of the Republic of Belarus

During the experimental research of metrological characteristics of standards photometric and LEDs units were working out:

- For continuous light sources with an axisymmetric filament is preferred photometric measurement method using integrating sphere.

- The standard can reproduce and store units of the correlated color temperature and chromaticity coordinates $\mathrm{x}, \mathrm{y}$. Residual systematic error of measurement of the correlated color temperature is not worse than $18 \mathrm{~K}$, the chromaticity coordinates $\mathrm{x}$ and $\mathrm{y}$ of 0.002 and 0.001 respectively.

- A range of reproducing of the unit of luminous flux is from 10 to $1500 \mathrm{~lm}$. Random component of the uncertainty of luminous flux unit reproduction is $0,2 \cdot 10^{-2}$. Unexcluded measurement error is $0,5 \cdot 10^{-2}$. Relative expanded uncertainty of the standard is $0.52 \%$.

\section{Absolute integrating sphere method for reproduction of the unit of luminous flux}

Absolute integrating sphere method for reproduction of the unit of luminous flux is based on the use of integrating sphere and external to it reference source of radiation [6]. Reference luminous flux created by the illuminance standard lamp and falls within the integrating sphere through the hole with a calibrated aperture diaphragm. Its value is determined by the illumination produced by the reference light source to the input aperture diaphragm. For an isotropic point source of radiation is equal to the luminous flux $\Phi_{\text {эт }}$

$$
\Phi_{\text {ЭТ }}=E_{\mathrm{V}} A
$$

where $E_{\mathrm{v}}-$ illuminance, produced by the reference light source to the input aperture diaphragm, lux; $A$ - area of the aperture diaphragm, $\mathrm{m}^{2}$.

Precision photometric head PSoT, manufactured by LMT (Germany), witch used for measurement of illuminance, produced by the reference light source to the input aperture diaphragm traceable to the National standard of the units of luminous intensity and illuminance of the Republic of Belarus.

When inner surface of the integrating sphere illuminated by the external source of radiation, spectrome-

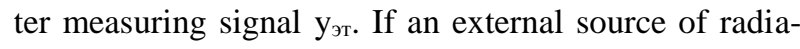
tion is blocked, and internal (calibrated) radiation source is turned on, the signal will be equal to $\mathrm{y}_{\text {кал. Knowing }}$ the value of the luminous flux $\Phi_{\text {эт }}$ attributed to the ex-

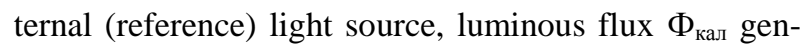
erated calibrated radiation source will be equal to

$$
\Phi_{\text {кал }}=f \Phi_{\text {эт }} \frac{y_{\text {кал }}}{y_{\text {эт }}}
$$

where $\mathrm{f}$ - correction factor. For ideal system $\mathrm{f}=1$.
For real system different from 1 and it's determined during research.

The external light source is used for periodic calibrations of the ISP 2000 integrating sphere, which is part of a photometric unit. The results of measurements carried out by an external source of radiation, are traceable to the units of illumination, spectral responsivity of radiation detectors and length, reproduced by the $\mathrm{Na}$ tional standards of the Republic of Belarus, located in BelGIM.

\section{Conclusions}

National standard of luminous flux of the Republic of Belarus are created. It has the following metrological characteristics:

- Range of reproducing of the unit of luminous flux is from 10 to $1500 \mathrm{~lm}$.

- Random component of the uncertainty of luminous flux unit reproduction is $0,2 \cdot 10^{-2}$.

- Unexcluded measurement error is $0,5 \cdot 10^{-2}$.

- Relative expanded uncertainty of the standard is $0.52 \%$.

\section{REFERENCES}

[1] Баковеи Н.В., Никоненко С.В., Скумс Д.В., Тарасова O.Б. Эталонная база Республики Беларусь в области фотометрии. / Баковеи Н.В., Никоненко С.В., Скумс Д.В., Тарасова О.Б.// Proc. Of 21 national scientific symposium "Metrology and metrology assurance 2011" Sozopol, Bulgaria. September 10-14, 2011

[2] Длугунович В.А., Исаевич А.В., Никоненко С. В. Эталонная и испытательная база в области фотоники / Длугунович В.А., Исаевич А.В., Никоненко С. В. // Наука и инновации. 2015. № 2 (144). - С. 19-21

[3] СТБ ИСО 23539/CIE S 010-2007. Фотометрия. Система физической фотометрии МКО. - Минск: Изд. БелГИСС, 2007. - 24 с.

[4] Lindemann, M., Maass, R., Sauter, G.: Robot goniophotometry at PTB. Metrologia 52, 167-194 (2015)

[5] Sametoglu, F.: Construction of two-axis goniophotometer for measurement of spatial distribution of a light source and calculation of luminous flux. Acta Phys. Pol. A 119, 783-791 (2011)

[6] Ohno, Y. Detector-Based Luminous Flux Calibration using the Absolute Integrating Sphere Method / Y. Ohno // Metrologia. 2000. Vol.35. № 4. - P. 473 - 478 